\title{
Hisar Urban Geographical Observational Cohort Study [HUG- OCS] - Aims and Objectives, Methodology, Future Plans
}

\author{
Sivachidambaram Kulandaivelan ${ }^{1}$, Mahamed Ateef ${ }^{2}$,Varun Singh ${ }^{1}$, \\ Rekha Chaturvedi ${ }^{1}$,Shabnam Joshi ${ }^{1}$,JaspreetKaur Malik ${ }^{1}$,Sonu Punia ${ }^{1}$, \\ Manoj Malik ${ }^{1}$,Dinesh Narwal $^{3}$, Monika Rani $^{1}$ \\ ${ }^{1}$ Assistant Professor, Dept. Of Physiotherapy, GJUST, Hisar-125001. Haryana.India. \\ ${ }^{2}$ Assistant Professor, Dept. Of Physiotherapy, CAMS, Majmaah University, Al-Majmaah, KSA. \\ ${ }^{3}$ Senior Physiotherapist, Jindal Steel And Power Limited, New Delhi, India.
}

\begin{abstract}
Introduction: The importance of physical activity, fitness on CVD risk factors are well established in western cohorts. However, there are no geographical cohorts available in India.

Aims and objectives: It has formed to identify role of physical activity, fitness, yoga practice and other sedentary behaviors on the development of some CVD risk factors (i.e) hypertension, diabetes and obesity in urban Indian population. The secondary objective is improved physical activity, fitness behavior, yoga practice and reduced sedentary behavior on the prognosis of above said risk factors once it developed.

Methodology: 1804 subjects (female 54.6\%; response rate 71.9\%) were selected through multi-stage random sampling technique in 6 different locations of urban Hisar city during summer 2016. Main eligibility criteria was age should be at least 30 years at the time of recruitment. Therapist assisted standard questionnaire was administered to collect baseline subjective data.Most of the outcome variables, muscular strength were measured objectively. Yoga practice; physical activity/sitting time through GPAQ are being measured now.

Future plan: Aerobic fitness through Rockport 1 mile walk test will be measured within 2 years. Subjectively measured physical activity, ADL and sedentary behaviors will be validated through pedometers. Usage of mobile phone, physiotherapists to modify the behavior of subjects and its effect on development and prognosis of CVD risk factors will be studied future.
\end{abstract}

Keywords: Cohort, Longitudinal study, Physical fitness, Chronic diseases, CVD risk factors

\section{Introduction}

Being physically active and fit has now shown many health benefits. ${ }^{[1,2]}$ Physicians in western countries are now even thinking of putting exercise as fifth vital sign for health assessment. ${ }^{[3]}$ It all started from a land mark article from Framingham Heart Study in 1967 that reported protective effect of physical activity on coronary heart diseases. This leads to form another cohort in 1970-Aerobic center longitudinal study (ACLS) from Cooper institute with the aim to find health outcomes associated with physical activity and cardiorespiratory fitness. Later in 1985-86 CARDIA study started with an aim of aerobic fitness at young age on CVD risk factors, diseases and mortality.These two along with several other longitudinal studies confirmed the findings of Framingham Heart Study. Recent meta-analysis shows that fitness prevent better than BMI in all-cause mortality and advise the readers to concentrate on fitness than mere physical activity and weight reduction alone ${ }^{[4]}$ Resultsare showing sedentary behaviors like sitting time, TV watching associated with greater risk of CVD risk factors, all-cause mortality independent of physical activity ${ }^{[5-7]}$ However, there are few cohorts available from India on physical activity with two known to us-one from southern India (Kerala) ${ }^{[8]}$, one from north India (Haryana) ${ }^{[9]}$ and few on physical fitness (hand-grip strength). ${ }^{[10]}$ Epidemiological studies based on physical activity and physical fitness over CVD risk factors are too less in India. To the best of our knowledge, there is no longitudinal study from India that sees the combined physical activity, physical fitness and sedentary behaviors on CVD risk factors in urban population.

There are several unanswered questions likehow much is the dose of physical activity for Indians? Indian specific practices like yoga does have productive role on CVD risk factors or not? If yes, what is the minimal dose of yoga and in which form?Indians are considered less fit as it is evident from Olympic and Asiad medal tally.So how much fitness is required by Indians to be prevented from CVD risk factors? Apart from these questions, Will all these four factors really prevent CVD risk factors in urban Indians or not? To answer these questions we decided to form a cohort with following objectives. 
Hisar Urban Geographical Observational Cohort Study [HUG-OCS] - Aims and Objectives, Methodology....

\section{Objectives}

Immediate ( $1^{\text {st } y e a r)-~ P r e v a l e n c e ~ o f ~ h y p e r t e n s i o n, ~ d i a b e t e s, ~ a b d o m i n a l ~ o b e s i t y, ~ p h y s i c a l ~ i n a c t i v i t y, ~}$ musculoskeletal pain and its correlates in urban population.Long term (5-20 years)- 5 year incidence rate (after 5, 10,15 and 20 years) of all-cause mortality, hypertension, diabetes, abdominal obesity, musculoskeletal pain and its determinants (based on exposure variables) in urban population. Role of physical activity, yoga practice, aerobic fitness, muscle strength and reduction of sedentary behavior as prognostic variables in people with hypertension, diabetes, abdominal obesity and musculoskeletal pain.

\section{Exposure Variables (all are modifiable)}

Primary- Physical activity, Yoga practice, Aerobic fitness, Muscular strength, Sedentary activities like Laptop/computer/TV watching, Sitting, Sleeping (Total 07 variables)

Secondary- Education, Income, Smoking, Alcohol consumption, Food habit, Ghee use (Total 06 variables)

\section{Outcome Variables}

Blood pressure (Hypertension), Fasting blood glucose (Diabetes), BMI (General obesity), Waist circumference (Abdominal Obesity), Musculoskeletal pain and all-cause mortality.

\section{Type of cohort}

\section{Methodology}

Prospective observational cohort on general population from specific geographical location(Hisar Urban Area)

\section{Sample collection from population:}

Population of this cohort was people living in urban area of Hisar city situated in Haryana state. Sample selected for this cohort was based on muti-stage random sampling technique. Sample size was calculated using online free software (OpenEpi) at 95\% significant level, $80 \%$ power with ratio of 1:7 for exposed versus unexposed and OR of 2.00 which yielded 1844. ${ }^{[11]}$ We decided at least 300 samples from one location so that difference between the locations can be studied easily in future, if need arises. 6 locations had to be selected with the sample size of 308 in each location to achieve our aims and objectives. Hisar city has 20 wards and each ward was divided into 1-6 logistic locations where,student volunteers thought feasibility (near to University), response and compliance rates will be high. 6 wards were selected (Ward No 1, 5, 8, 14, 16 and 20) and one location from each ward was randomly selected by corresponding author.Student volunteers randomly selected one house and invited the master of the house to participate in this cohort. If he agrees, all members above 30 years old were included in cohort after getting initial verbal consent from eachfollowed by administration of a questionnaire and measurement of other outcome variables. Participants also provided their mobile number along with written willingness to join the cohort at the end of questionnaire. If master of the house not agreed to participate, volunteers visited next house using left thumb rule until they reach desired sample size (i.e) 308 from each location.

Baseline data was collected by 3 master degree student volunteers through door-to-door visit in summer 2016 which was validated telephonically by final year bachelor degree student volunteer (this reduced the sample size from 1848 to $1804 ; 44$ subjects were removed due to high mismatched responses). Follow-up of outcome variables data collection along with physical activity and sedentary activity measurement, yoga practice is undergoing now by 2 master degree student volunteers (Response rate above $90 \%$ in one location). All student volunteers were trained and motivated/guided by corresponding author and were acknowledged at the end of this paper.

\section{Questionnaire:}

Pre-designed questionnaire (in English), modified from pilot study done in 2015, was administered to the individual participants and therapist assisted if there was a problem to read/understand. Following parameters were self-reported: age, height, weight (are being objectively measured now), occupation, community [general (OC), backward (BC) and scheduled caste (SC)], education, income, smoking, alcohol habits, food habit, ghee use, ADL activity, computer/laptop/TV watching time, sitting time, sleeping time, self-reported hypertension, family history of hypertension, self-reported diabetes, family history of diabetes. 


\section{Measurement of Outcome variables:}

Musculoskeletal pain was defined as pain that required meeting physician or pain that prevented from carrying normal ADLfor at least 3 days in the past 12 months. Modified Nordic musculoskeletal questionnaire (only middle 2 sections) with diagram used by de Barros and Alexandre ${ }^{[12]}$, was used for this purpose and was recorded for major joints (i.e) neck, shoulder, elbow, wrist, low back, hip, knee and ankle joints. All outcome variables except musculoskeletal pain were measured in early morning (6-9.30 AM) after overnight fasting (6-8 hours rest after dinner) in a manner described below.

Blood pressure was measured using automatic digital sphygmomanometer [OMRON ${ }^{\circledR}$, Binh Duong, Vietnam] which is operated by batteries. Subject was asked to sit without support in relaxed manner while keeping hands in knees, elbow in extension and forearm supination. Cuff was fit into the left arm, while the tube connected to the instrument kept above the brachial artery. Apparatus always kept at heart level and the body of apparatus has 'start' button which has to be pressed before reading. This results automatic inflation of cuff to the level above the SBP, then deflated; at the end it shows SBP, DBP, pulse rate (HR) values. The same procedure was repeated thrice and the middle value was recorded with both higher and lower values removed.

Fasting blood glucose was measured by hand-held portable glucometer [ACCU-CHECK Active, Mannheim, Germany]. After sterilizing the subject's ring finger using spirit swab, it was pricked using sterile softclix lancets. Initial oozing blood was wiped out, and then one drop blood was taken by sensor side of glucostrips. After approximately 5 seconds, display section shows blood glucose level in $\mathrm{mg}$. $\mathrm{dL}^{-1}$. The whole procedure was repeated if only extreme values comes $\left(<60 \mathrm{mg} \cdot \mathrm{dL}^{-1}\right.$ or $>200 \mathrm{mg} \cdot \mathrm{dL}^{-1}$ without self-reported diabetes $)$ and higher reading in lower values, lower readings in higher values were recorded.

Waist circumference was measured using non-elastic inch tape in early morning after bladder and bowel emptying. Subject was asked to stand with minimal and loose clothing. Measurement site was decided by mid-way between $12^{\text {th }}$ rib and ASIS (anterior superior iliac spine). Measurement was recorded in the assessment form, questionnaire, to the nearest centimeter $(\mathrm{cm})$ value.BMI was calculated from self-reported values of weight in Kilogram and height in meters. The formula used was weight divided by height ${ }^{2}$.

\section{Measurement of Primary exposure variables:}

Self-reported physical activity is being measured using global physical activity questionnaire (GPAQ) as this is easy to administer and has been validated in India. Physical inactivity will be termed if the subject is not meeting 600 MET minutes per week criteria.

Yoga practice is being measured using questionnaire. Questions included were whether subject practice yoga or not (no, yes/occasional, yes/regular), if yes frequency (per week or month), duration (hours per week) and type [asana (posture flow), pranayama (breathing exercise), meditation (concentration, chanting) and kiriyas (cleansing technique)].

Aerobic fitness will be measured using submaximal Rockport 1-mile walk test as it is easy to administer with less complications when medical personnel are not present during test. The test will be administered in treadmill where speed will be self-selected by subjects. Subject will not be allowed to touch hand-rail or allowed to touch rail to maintain balance. Time taken to complete the test (in hundredth of minute), heart rate at the end of test will be measured to calculate $\mathrm{VO}_{2}$ max using standard formula. Strength of this test is since heart rate is used in $\mathrm{VO}_{2}$ max calculation, speed of subject walking will not affect aerobic fitness (i.e) faster walking will increase heart rate vice-versa, fitter person will have less heart rate in given walking speed. Disadvantage of this test is administration of cardiovascular drugs will affect the heart rate hence $\mathrm{VO}_{2}$ calculation.

Hand-grip strength (HGS)was measured using Jamar digital hand-held hydrolic hand dynamometer [Base Line Evaluation set, Fabrication Enterprises Inc, NY]. HGS measurement was measured in sitting position for both right and left side. Each subject was asked to maintain the desired upper limb position (shoulder adducted, $0^{\circ}$ flexion; elbow in $90^{\circ}$ flexion; forearm mid-pronation), which was physically demonstrated by the therapist, and asked to press as hard as possible for 5 seconds (command given was press...one...two...three...four...five...relax). The procedure was repeated three times in right and left hand. One minute rest was given between trials. Average of three was recorded in the assessment form as $\mathrm{Kg}$.

Household ADL activity was measured by questionnaire. Household activities include cooking, washing clothes, cleaning floor, roof, vehicle and utensils etc, gardening, preparing children and elders, walking/cycling for getting water, vegetables, groceries, milk etc. Questions asked for both week days and week end. Value was recorded in hours spend on household ADL activities per week. 
Hisar Urban Geographical Observational Cohort Study [HUG-OCS] - Aims and Objectives, Methodology....

Table 1: Baseline values of different variables in all six locations for comparison

\begin{tabular}{|c|c|c|c|c|c|c|c|c|}
\hline S.N & Variable & Location l & Location 2 & Location 3 & Location 4 & Location 5 & Location 6 & 'P'value \\
\hline & Sample Size & 301 & 300 & 298 & 298 & 304 & 303 & \\
\hline & Response rate (\%) & 80.21 & 70.64 & 65.25 & 85.79 & 75.86 & 60.16 & \\
\hline \multirow[t]{2}{*}{1} & Age (years) $($ mean $\pm S D)$ & $45.34 \pm 12.33$ & $46.96 \pm 11.90$ & $49.97 \pm 12.89$ & $46.73 \pm 12.71$ & $48.33 \pm 13.85$ & $50.70 \pm 13.08$ & 0.000 \\
\hline & Age (years)(Min-Max value) & $30-80$ & $30-83$ & $30-86$ & $30-80$ & $30-87$ & $28-88$ & \\
\hline 2 & Sex (Female in \%) & 55.8 & 57.0 & 50.0 & 59.7 & 52.3 & 52.8 & 0.178 \\
\hline 3 & Community $(\mathrm{BC} / \mathrm{SC}$ in $\%)$ & 71.1 & 10.3 & 14.4 & 59.8 & 10.5 & 6.3 & 0.000 \\
\hline 4 & Illiteracy $(\%)$ & 25.3 & 6.0 & 5.2 & 15.8 & 5.3 & 4.0 & 0.000 \\
\hline 5 & Smoking $(\%)$ & 16.9 & 8.7 & 8.1 & 10.1 & 9.5 & 4.6 & 0.000 \\
\hline 6 & Alcohol consumption $(\%)$ & 11.0 & 15.7 & 7.0 & 12.8 & 8.9 & 6.6 & 0.001 \\
\hline 7 & FV usage $(\%$ of $<1$ time/day) & 67.2 & 22.7 & 11.8 & 21.1 & 21.4 & 17.5 & 0.000 \\
\hline 8 & Egg or Non-Vegetarian $(\%)$ & 3.3 & 4.3 & 5.4 & 12.0 & 5.2 & 7.6 & 0.000 \\
\hline \multirow[t]{2}{*}{9} & $\mathrm{BMI}\left(\mathrm{Kg}, \mathrm{m}^{-2}\right)($ mean $\pm \mathrm{SD})$ & $24.77 \pm 4.87$ & $25.92 \pm 4.39$ & $25.71 \pm 3.70$ & $25.55 \pm 4.30$ & $26.95 \pm 5.30$ & $26.81 \pm 4.13$ & 0.000 \\
\hline & BMI $\left(\mathrm{Kg} \cdot \mathrm{m}^{-2}\right)$ (Min-Max value) & $15.49-40.05$ & $16.49-42.75$ & $14.92-38.42$ & $12.72-43.11$ & $15.56-47.34$ & $17.46-40.90$ & \\
\hline \multirow[t]{2}{*}{10} & Waist Circumference $(\mathrm{cm})($ meantSD) & $88.84 \pm 12.27$ & $96.81 \pm 11.50$ & $92.06 \pm 10.24$ & $92.98 \pm 12.02$ & $96.83 \pm 12.93$ & $94.86 \pm 10.95$ & 0.000 \\
\hline & Waist Circumference $(\mathrm{cm})$ (Min-Max) & $46-123$ & $55-136$ & $61-122$ & $46-130$ & $39-138$ & $57-146$ & \\
\hline \multirow[t]{2}{*}{11} & Income (in Rs/month)(mean) & 14585.96 & 27598.66 & 37549.15 & 37589.13 & 30738.16 & 44217.82 & 0.000 \\
\hline & Income (in Rs/month)(Min-Max) & $3000-150000$ & $2000-100000$ & $5000-180000$ & $4000-200000$ & $5000-150000$ & $6000-100000$ & \\
\hline \multirow[t]{2}{*}{12} & $\mathrm{ADL}(\mathrm{hrs} /$ week $)($ mean $\pm \mathrm{SD})$ & $24.86 \pm 16.25$ & $26.02 \pm 16.29$ & $16.85 \pm 15.16$ & $20.87 \pm 19.78$ & $19.93 \pm 17.02$ & $21.74 \pm 13.94$ & 0.000 \\
\hline & ADL(hrs/week)(Min-Max value) & $0-63$ & $1-70$ & $0-63$ & 0.70 & 0.70 & $2-63$ & \\
\hline \multirow[t]{2}{*}{13} & Sitting(hrs/week)(mean \pm SD) & $31.24 \pm 11.58$ & $24.01 \pm 16.08$ & $34.40 \pm 11.77$ & $22.26 \pm 17.26$ & $29.90 \pm 13.20$ & $33.69 \pm 10.97$ & 0.000 \\
\hline & Sitting(hrs/week)(Min-Max value) & 0.70 & $4-70$ & $7-70$ & $0-84$ & 0.70 & 7.70 & \\
\hline \multirow[t]{2}{*}{14} & TV watching (hrs/week)(mean \pm SD) & $11.05 \pm 7.25$ & $12.35 \pm 9.55$ & $8.41 \pm 5.78$ & $9.25 \pm 8.65$ & $11.67 \pm 9.28$ & $11.47 \pm 8.80$ & 0.013 \\
\hline & TV watching (hrs/week)(Min-Max) & $0-84$ & $1-84$ & $0-35$ & $0-70$ & 0.70 & $0-84$ & \\
\hline \multirow[t]{2}{*}{15} & Sleeping (hrs/week)(mean \pm SD) & $54.03 \pm 9.72$ & $53.96 \pm 10.60$ & $50.89 \pm 7.06$ & $54.79 \pm 9.88$ & $53.78 \pm 9.17$ & $50.86 \pm 10.88$ & 0.000 \\
\hline & Sleeping(hrs/week)(Min-Max value) & $18-84$ & $28-98$ & $35-70$ & $30-98$ & $25-91$ & $20-98$ & \\
\hline \multirow[t]{2}{*}{16} & $\mathrm{SBP}(\mathrm{mmHg})(\mathrm{mean}=\mathrm{SD})$ & $131.27 \pm 19.4$ & $133.24 \pm 20.0$ & $131.78 \pm 16.9$ & $128.41 \pm 19.1$ & $131.91 \pm 17.2$ & $131.50 \pm 17.4$ & 0.046 \\
\hline & $\mathrm{SBP}(\mathrm{mmHg})(\mathrm{Min}-\mathrm{Max}$ value $)$ & $91-215$ & $92-217$ & $99-190$ & $93-191$ & $93-197$ & $95-203$ & \\
\hline \multirow[t]{2}{*}{17} & $\mathrm{DBP}(\mathrm{mmHg})($ mean $\pm \mathrm{SD})$ & $85.94 \pm 11.43$ & $88.36 \pm 12.34$ & $85.13 \pm 10.32$ & $85.03 \pm 11.32$ & $85.91 \pm 10.26$ & $85.34 \pm 10.18$ & 0.002 \\
\hline & $\mathrm{DBP}(\mathrm{mmHg})(\mathrm{Min}-\mathrm{Max}$ value $)$ & $55-140$ & $56-139$ & $43-129$ & $61-121$ & $57-128$ & $42-122$ & \\
\hline \multirow[t]{2}{*}{18} & $\mathrm{FBG}(\mathrm{mg} / \mathrm{dL})($ mean $\pm \mathrm{SD})$ & $97.41 \pm 35.32$ & $114.86 \pm 41.5$ & $95.23 \pm 33.14$ & $111.78 \pm 40.5$ & $108.60 \pm 40.1$ & $97.46 \pm 36.67$ & 0.000 \\
\hline & FBG $(\mathrm{mg} / \mathrm{dL})($ Min-Max value $)$ & $63-417$ & $57-346$ & $59-300$ & $56-465$ & $65-298$ & $57-281$ & \\
\hline \multirow[t]{2}{*}{19} & Right HGS $(\mathrm{Kg})($ mean $\pm \mathrm{SD})$ & $25.58 \pm 9.52$ & $28.77 \pm 9.69$ & $29.07 \pm 9.46$ & $29.40 \pm 10.34$ & $27.01 \pm 10.33$ & $29.03 \pm 9.70$ & 0.000 \\
\hline & Right HGS(Kg) (Min-Max value) & $5.30-56.20$ & $3.50-59.00$ & $8.50-56.10$ & $7.60-58.00$ & $5.00-57.30$ & $7.30-52.40$ & \\
\hline \multirow[t]{2}{*}{20} & Left HGS $(\mathrm{Kg})($ mean $\pm \mathrm{SD})$ & $23.95 \pm 9.47$ & $26.56 \pm 9.57$ & $27.11 \pm 9.57$ & $27.33 \pm 10.12$ & $25.12 \pm 9.94$ & $27.74 \pm 10.13$ & 0.000 \\
\hline & Left HGS(Kg) (Min-Max value) & $1.20-52.20$ & $0.00-54.90$ & $3.60-58.30$ & $6.00-58.00$ & $3.90-58.90$ & $5.10-72.60$ & Activa \\
\hline
\end{tabular}

Abbreviations: SD- standard deviation; Min- minimum; Max- maximum; BC- backward community; SC- scheduled caste; FV- fruit and vegetables; BMI- body mass index; ADL- activities of daily living; SBP- systolic blood pressure; DBP- diastolic blood pressure; FBG- fasting blood glucose; HGS- hand-grip strength

Note: 'p' values were calculated from one-way ANNOVA for continuous variables and chi-square test for string or categorical variables

TV watching time included watching serials, movies, songs, reality shows, sports matches, live shows, bhajans etc. in sitting position. These may be viewed in theater, TV, computer or lap top, mobile. This item also included surfing internet, social media use, chatting etc. in mobile. Computer or laptop use for billing, office work, and study purpose apart from above activities was also part of this item. Condition for this item was subject should be in sitting position. Questions asked for both week days and week end. Value was recorded inhours spend on TV watching per week. Classification will be used as per Grontved and $\mathrm{Hu}^{[6]}$ study result.

Sitting time included activities spend in sitting position other than above item (i.e) chatting with friends, reading newspaper, office/shop, listening music, travel etc. Questions asked for both week days and week end. Value was recorded in hours spend per week. Classification will be used as per Chau et al. ${ }^{[14]}$ study result.

Sleeping time included time spend in bed during night as well as day (napping). Questions asked for both week days and week end. Value was recorded in hours spend per week. Definition for normal, short and long sleep will be used as per Cappuccio et al. ${ }^{[15]}$

\section{Measurement of Secondary exposure variables:}

All secondary exposure variables were self-reported. Education (classified into illiterate, upto $9^{\text {th }}$ class, $10^{\text {th }}$ class, $12^{\text {th }}$ class, undergraduate, postgraduate, MPhill, PhD), Income as on summer 2015 (in Rs per month), smoking [yes/no; if yes frequency (number cigarettes per day or week)], alcohol habits [yes/no; if yes frequency (number of 
times per week or month)], food type (Vegetarian or Non-vegetarian including egg use), ghee use [yes/no; if yes frequency (number spoons per week)].Income was classified according to Kuppuswamy's socio-economic status scale $\left(7\right.$ categories). ${ }^{[16]}$

\section{Future Plans}

Apart from measuring aerobic fitness by 2020 , we want to validate the physical activity, sedentary behaviors assessed by our questionnaire using pedometers. All the outcome variables, exposure variables will be measured at 5 year intervals to calculate incident rate and identify the determinants for CVD risk factors. We will also monitor the prognosis of CVD risk with reference to primary exposure variables. Use of physiotherapist in community level to promote physical activity, fitness will be another objective. Recent study from India shows promising result to control diabetes by using mobile technology. ${ }^{[17,18]}$ Significance of mobile use in promoting physical activity, fitness- thus preventing CVD risk will be objective in future.

Ethical clearance: The whole procedure was retrospectively approved by institutional ethical committee vide letter no PTY/ 2016/ 555 dated $14^{\text {th }}$ October 2016.

Source of Funding: Corresponding author (SivachidambaramKulandaivelan), Second author (Mohamed Ateef), contribution from volunteers are currently source of funding for this project.

\section{Acknowledgements}

We would like to thank Prof SK Singh, Chairman, Dept. of Physiotherapy, GJUST, Hisar who constantly motivating and strategically supporting us. We would like to thank following student volunteers for helping data collection process: Dr Rahul Bali (PT), DrRavinder Kumar (PT), DrKamini (PT), DrUshaPanihar (PT), DrSumedhaSangwan (PT) and Dr Nancy Singla (PT).Last but not the least;We thank all the participants for giving consent to this noble cause in a developing country like India.

\section{References}

[1]. Blair SN, Cheng Y, Holder JS. Is physical activity or physical fitness more important in defining health benefits? Med Sci Sports Exerc. 2001;33(6):S379-S399. PubMed Link: https://www.ncbi.nlm.nih.gov/pubmed/11427763

[2]. Reiner M, Niermann C, Jekauc D, Woll A. Long-term health benefits of physical activity- A systematic review of longitudinal studies. BMC Public Health. 2013;13:813.PubMed Link: https://www.ncbi.nlm.nih.gov/pubmed/24010994

[3]. Sallis R. Developing healthcare systems to support exercise: Exercise as the fifth vital sign (Editorial). Br J Sports Med. 2011;45:473474.PubMed Link: https://www.ncbi.nlm.nih.gov/pubmed/21292925

[4]. Barry VW, Baruth M, Beets MW, Durstine JL, Liu J, Blair SN. Fitness vs fatness on all-cause mortality: A meta-analysis. ProgCardiovasc Dis. 2014;56(4):382-90. PubMed Link: https://www.ncbi.nlm.nih.gov/pubmed/24438729

[5]. Thorp AA, Owen N, Neuhaus M, Dunstan DW. Sedentary behaviors and subsequent health outcomes in adults. A systematic review of longitudinal studies, 1996-2011. Am J Prev Med. 2011;41(2):207-215.PubMed Link: https://www.ncbi.nlm.nih.gov/pubmed/21767729

[6]. Grontved A, Hu FB. Television viewing and risk of type 2 diabetes, cardiovascular disease, and all-cause mortality. A meta-analysis. JAMA. 2011;305(23):2448-2455.PubMed Link: https://www.ncbi.nlm.nih.gov/pubmed/21673296

[7]. Rezende LF, Sa TH, Mielke GI, Viscondi JY, Rey-Lopez JP, Garcia LM. All-cause mortality attributable to sitting time: Analysis of 54 countries worldwide. Am J Prev Med. 2016;51(2):253-63. PubMed Link: https://www.ncbi.nlm.nih.gov/pubmed/27017420

[8]. Soman CR, Shahulhameed S, Ramankutty V et al. Cohort profile: The PROLIFE study in Kerala, India. Int JEpidemiol. 2011;40:1014.PubMed Link: https://www.ncbi.nlm.nih.gov/pubmed/19740760

[9]. Kant S, Misra P, Gupta S et al. The Ballabgarh health and demographic surveillance system (CRHSP-AIIMS). Int J Epidemiol. 2013;42:758-768.PubMed Link: https://www.ncbi.nlm.nih.gov/pubmed/23620380

[10]. Leong DP, Teo KK, Rangarajan S, Lopez-Jaramillo et al. Prognostic value of grip strength: Findings from prospective urban rural epidemiology (PURE) study. Lancet. 2015;386(9990):266-73. PubMed Link: https://www.ncbi.nlm.nih.gov/pubmed/25982160

[11]. 'OpenEpi' Sample Size Calculator for cohort study available freely from http://www.openepi.com/SampleSize/SSCohort.htm assessed finally on January 2016.

[12]. de Barros EN, Alexandre NM. Cross-cultural adaptation of the Nordic musculoskeletal questionnaire. IntNurs Rev. 2003;50:101108.PubMed Link: https://www.ncbi.nlm.nih.gov/pubmed/12752909

[13]. WHO. Global recommendations on physical activity for health. Geneva: World Health Organization. 2010.

[14]. Chau JY, Grunseit AC, Chey T, et al. Daily sitting time and all-cause mortality: A meta-analysis. PLoS ONE. 2013;8(11):e80000.PubMed Link: https://www.ncbi.nlm.nih.gov/pubmed/24236168

[15]. Cappuccio FP, D'Elia L, Strazzullo P, Miller. Sleep duration and all-cause mortality: A systematic review and meta-analysis of prospective studies. Sleep. 2010;33(5):585-92.PubMed Link: https://www.ncbi.nlm.nih.gov/pubmed/20469800

[16]. Thakkar C, Rawat CMS. Kuppuswamy's socio-economic status scale: Updating income ranges for the year 2015. Indian J Comm Health. 2015;27(4):415-17.

[17]. Ramachandran A, Snehalatha C, Ram J, et al. Effectiveness of mobile phone messaging in prevention of type 2 diabetes by lifestyle modification in men in India: A prospective parallel-group, randomized controlled trial. Lancet Diabetes Endocrinol. 2013;1:191-98.

[18]. Pfammatter A, Spring B, Saligram N, et al. mHealth intervention to improve diabetes risk behaviors in India: A prospective, parallel group cohort study. J Med Internet Res. 2016;18:e207.PubMed Link: https://www.ncbi.nlm.nih.gov/pubmed/27496271 